\section{$\Psi$ \\ Revista \\ de Psicologia}

ISSN 2179-1740

\title{
MOTIVAÇÕES E DIFICULDADES VIVENCIADAS POR JOVENS EMPREENDEDORES: ESTUDO QUALITATIVO
}

MOTIVATIONS AND DIFFICULTIES EXPERIENCED BY YOUNG ENTREPRENEURS: QUALITATIVE STUDY

\author{
Larissa Paula Martins ${ }^{1}$ \\ Heila Magali da Silva Veiga ${ }^{2}$ \\ Pedro Afonso $\mathrm{Cortez}^{3}$
}

\section{Resumo}

O empreendedorismo vem se destacando como uma nova forma de inserção no mercado de trabalho, principalmente para os jovens. Assim, 0 presente estudo objetivou compreender as motivações e dificuldades vivenciadas por jovens ao longo do processo de empreender. A amostra foi composta por seis jovens empreendedores, sendo cinco mulheres e um homem. Foram aplicadas entrevistas semiestruturadas, analisadas por meio de análise de conteúdo. A análise das entrevistas resultou em categorias relacionadas com motivações, dificuldades e características dos empreendedores. As características pessoais relatadas pelos jovens empreendedores foram compatíveis com a literatura, abrangendo assumir riscos, comunicação, responsabilidade e criatividade. As categorias mais frequentes como motivações para empreender foram prestígio, influências de terceiros e familiares, necessidades e oportunidades. As dificuldades elencadas associaram-se a iniciar o projeto, adesão dos clientes, liderança, falta de planejamento e desgaste físico e mental. Por meio das categorias elencadas, nota-se que efetivar 0 empreendedorismo entre jovens requer ações sistemáticas por meio de políticas públicas atreladas aos campos de saúde, educação e trabalho.

Palavras-chave: empreendedorismo; dificuldades; motivação; jovem

\section{Abstract}

Entrepreneurship has emerged as a new form of insertion in the labor market, especially for young people. Thus, the present study aimed to understand the motivations and difficulties experienced by young people throughout the process of undertaking. The sample consisted of six young entrepreneurs, five women and one man. Semistructured interviews were applied, analyzed through content analysis. The analysis of the interviews resulted in categories related to the motivations, difficulties and characteristics of the entrepreneurs. The personal characteristics reported by the young entrepreneurs were compatible with the literature, including taking risks, communication, responsibility and creativity. The most frequent categories as motivations to undertake were prestige, influences of third and family, needs and opportunities. The difficulties highlighted were associated with initiating the project, customer support, leadership, lack of planning and physical and mental exhaustion. Through the categories listed, it is noted that effective entrepreneurship among young people requires systematic actions through public policies linked to the fields of health, education, and work.

Keywords: entrepreneurship; difficulties; motivation; young

\footnotetext{
1 Psicóloga, Universidade Federal de Uberlândia, MG. Brasil. larissapaulamartins0@gmail.com. https://orcid.org/0000-0001-7088-3599

2 Doutorado, Universidade Federal de Uberlândia, MG. Brasil. heila.veiga@gmail.com. http://orcid.org/0000-0002-7429-8124

3 Doutorado, Universidade São Francisco, SP. Brasil. cor.afonso@gmail.com. https://orcid.org/0000-0003-0107-2033
} 


\section{INTRODUÇÃO}

O empreendedorismo vem chamando a atenção como uma alternativa de trabalho na vida de muitas pessoas, especialmente em um cenário de escassez de emprego ele se mostra como uma estratégia eficaz para identificar novas oportunidades de trabalho e a geração de renda. Desta forma, é fundamental apreender o que motiva e dificulta os sujeitos a empreender, uma vez que os empreendedores têm um papel importante na economia e contribuem para a empregabilidade, produtividade e inovação (Gorgievski \& Stephan, 2016; Obschonka, Silbereisen \& Schmitt-Rodermund, 2010; Van Praag \& Versloot, 2007). Na esfera acadêmica, a pesquisa sobre empreendedorismo está em prodigalidade e continua se expandindo pela possibilidade de impactar nas variáveis antecedentes que maximizam o nível de atividade empreendedora (Veiga, Demo, \& Neiva, 2017; Cortez \& Veiga, 2018; Wiklund, Davidsson, Audretsch \& Karlsson, 2011).

Entre os adultos jovens, que não possuem experiência profissional, o empreendedorismo tem sido uma estratégia para inserção no mercado de trabalho (Conaje, 2016; Sinha et al., 2016) e, entre as motivações para empreender, desse público, tem-se, por exemplo, autonomia, busca por independência, falta de oportunidades atrativas, necessidade de colaborar no custeio de despesas (Ferreira, Loiola, \& Gondim, 2017). De acordo com 0 Estatuto da Juventude (Lei 12.852, 2013) esse grupo é formado por jovens com idade entre 15 a 29 anos. No Brasil, 0 grupo etário com maior número de empreendedores iniciais é formado por jovens de 18 a 34 anos, sendo essa a maior taxa entre os países da América Latina e do BRIS (Brasil, Rússia, Índia e África do Sul) (Bulgacov, Cunha, Camargo, Meza, \& Bugacov, 2011).

Cabe destacar ainda que os jovens oriundos de países desenvolvidos apresentam taxas menores no empreendedorismo do que jovens de países emergentes. Na América Latina, assim como em outros países em desenvolvimento, o jovem se vê obrigado a inserir-se no mercado de trabalho para garantir sua sobrevivência ou formação, diferentemente dos países desenvolvidos, nos quais os jovens são estimulados a aumentar o tempo de formação e retardar a entrada no mercado de trabalho (Bulgacov et al., 2011). Nesse contexto, os empreendedores podem ser classificados em dois grupos: empreendedores por necessidade e empreendedores por oportunidade (Vale, Côrrea, \& Reis, 2014). No primeiro grupo a decisão de iniciar um empreendimento está pautada na não existência de outras opções para a geração de renda para si e suas famílias (Machado, Cruz, Chinelato, \& Silva, 2015; Ruppenthal \& Cimadon, 2012). No segundo caso, as pessoas identificam novas possibilidades para a geração de renda e emprego mesmo quando possuem alternativas de emprego (Brasil, 2012).

No Brasil, os empreendedores por oportunidade são maioria, sendo que a relação oportunidade versus necessidade tem sido superior a 1,4 desde 0 ano de 2007. Em 2010, para cada empreendedor por necessidade havia outros 2,1 que empreenderam por oportunidade (Brasil, 2012). Por sua vez, em 2014, para cada empreendedor que iniciou suas atividades por necessidade, 2,4 o fizeram por oportunidade (GEM, 2017). No país, existem políticas públicas, definidas pelo Ministério do Desenvolvimento, Indústria e Comércio Exterior - MDIC (2012) - que visam 0 desenvolvimento do empreendedorismo permitindo o planejamento, o monitoramento, a execução e o controle das ações empreendedoras, a fim de promover uma união entre os interesses locais e individuais com os interesses governamentais (Sarfati, 2013).

Pode-se citar como exemplo de políticas públicas o "Programa Nacional de Microcrédito", do Ministério da Fazenda que visa elevar o padrão de vida da população de baixa renda através do empreendedorismo; 
"Garantia-Safra", do Ministério do Desenvolvimento Agrário, que visa a segurança e tranquilidade do exercício da atividade agrícola no semi-árido brasileiro; "Programa de Capacitação em Projetos Culturais", do Ministério da Cultura, que visa atender à demanda do setor cultural, tanto de inciativa pública quanto privada, para desenvolvimento das etapas do negócio cultural; entre outros (Valentim \& Peruzzo, 2018). Esses programas exemplificam esforços nacionais para a promoção da atividade empreendedora no nível macro, mas possuem lacunas ao não incluir uma compreensão micro do processo empreendedor.

Neste sentido, apreender características pessoais, motivações e dificuldades vivenciados pelo agente empreendedor ao longo da criação do próprio negócio se torna urgente, uma vez que possibilita compreensões adicionais ao tema que pode otimizar a proposição de políticas para fomentar o nível de atividade empreendedora brasileira. Considerando, portanto, as evidências expostas, as quais tratam da relevância de aprimorar na compreensão do empreendedorismo de forma processual entre adultos jovens, o objetivo geral do presente estudo foi compreender as motivações e dificuldades vivenciadas pelos jovens ao longo do processo de empreender.

\section{EMPREENDEDORISMO COMO OBJETO DE INVESTIGAÇÃO PSICOLÓGICA}

Compreender o empreendedorismo na Psicologia perpassa por analisar o sujeito empreendedor e seus relatos e aspectos pessoais. Ao analisar a literatura se observa que não há um acordo sobre quem introduziu 0 conceito do empreendedor, mas parece haver consenso que a palavra entrepreneur foi usada pela primeira vez, em 1725, pelo economista irlandês Richard Cantillon para designar o "indivíduo que assume riscos", ou seja, o empreendedor (Dantas, 2008). Cantillon desenvolveu uma das primeiras teorias do empreendedor, ao observar 0 fracasso de um empreendedor chamado Joh'n Law, que tentou aumentar o valor das ações de sua empresa para mais que seu patrimônio ao findar desta, sendo, portanto, um sujeito que assume riscos.

Cantillon (1755/2001) também é considerado por muitos como um dos criadores do termo empreendedorismo, e suas primeiras referências datam de 1755. Ele diferenciou o empreendedor (o indivíduo capaz de assumir riscos) do capitalista (o que fornece o capital). Em sua obra, "Ensaio sobre a natureza do comércio" Cantillon caracteriza o empreendedor como sendo aquele que vive na incerteza, devendo ter capacidade de reflexão e de previsão, bem como de ser racional. Para o autor, portanto, o empreendedor é um indivíduo racional, inserido em uma sociedade mercantil, na qual há a regulação do mercado pela concorrência, e que deve ter a capacidade para avaliar possíveis acontecimentos e calcular os seus riscos. Enfim, o autor define que o empreendedor é um indivíduo capaz de decidir racionalmente, assumindo riscos para gerir uma empresa, tendo como objetivo final alcançar o lucro.

Jean Baptiste Say (1767-1832) também trouxe esse termo no cenário econômico da criação e gestão de novos negócios (Bittar, Bastos, \& Moreira, 2014). Na concepção do autor, o empreendedor é o indivíduo responsável por unir todos os fatores de produção e descobrir no valor dos produtos a reorganização de todo capital que ele emprega, o juro, o valor dos salários, o aluguel, assim como os lucros que the pertencem. Sua definição de empreendedorismo, portanto, está mais voltada para os negócios. Ele prega que os requisitos primordiais para um empreendedor são: julgamento, perseverança, conhecimento sobre o mundo e sobre o negócio e possuir a arte de superintendência e da administração (Say, [1767-1832], 2001).

Voltando-se para uma concepção etimológica, o termo "empreendedor" surgiu na língua portuguesa no século XVI (Baggio \& Baggio, 2014). Em anos posteriores, outros autores utilizaram o termo para tratar de diferentes 
atividades comerciais, como Jean- Baptiste Say, em 1814, para indivíduos que migram seus recursos econômicos de um setor de produtividade baixa para um setor de produtividade alta. Ele afirmou que o empreendedorismo estava incluso aos fatores de produção, que são: terra, trabalho, capital e empreendedorismo (Dantas, 2008).

Outros autores também trouxeram suas contribuições, tal qual Carl Menger, em 1871, ao dizer que 0 empreendedor é aquele que pode antecipar necessidades que ainda estão por vir. Também Frank Knight, em 1921, ao afirmar que o empreendedor se distingue por suas capacidades de lidar com aquilo que é incerto. Este classificou a incerteza em três tipos: o risco, a ambiguidade e o que ele chamou de Incerteza Verdadeira ou Incerteza Knightiana, que não pode ser predita ou estimada (Dantas, 2008).

Schumpeter $(1983,1984)$, economista, considerado um dos principais expoentes da temática, relaciona 0 empreendedor ao desenvolvimento da economia e à inovação. Esse autor define o empreendedor como aquele capaz de colocar sua ideia inovadora em prática e torná-la um sucesso, substituindo, assim, outras ideias/produtos que já estavam no mercado, ação esta que ele chama de "destruição criativa". Conforme as oportunidades fossem identificadas, revitaliza-se ideias e empresas já existentes ou criam-se novas. Dessa forma, ele coloca a "destruição criativa" não só como dinamizadora das indústrias, mas também como responsável pelo crescimento econômico em longo prazo porque a destruição criativa é responsável por corromper os monopólios gerando novos ciclos de desenvolvimento econômico.

Partindo, então, da literatura supracitada, é possivel apreender que o empreendedorismo é um fenômeno multinivel com diferentes definições para a concepção de empreendedor (Leon, Gorgievski, \& Lukes, 2008). Esse tema é investigado sob diversos enfoques, sendo a sociologia, a economia e a psicologia campos de conhecimento que mais trazem contribuições para o estudo do empreendedorismo (Frese \& Gielnik, 2014; Gorgievski \& Stephan, 2016; Vale, 2014). Ao confrontar as abordagens teóricas apresentadas se observa que as abordagens econômica e psicológica focam mais em um determinado ator, com características individuais, enquanto que as abordagens sociológica e sociológica-econômica enfocam um dado contexto ou estrutura social (Vale, 2014). As abordagens parecem concordar no que diz respeito ao caráter inovador do empreendedor, bem como aquele que está atento às oportunidades. Ademais, ele ainda aparece como um agente capaz de promover o crescimento da economia.

\section{CARACTERÍSTICAS PESSOAIS DO AGENTE EMPREENDEDOR E PROCESSO DE EMPREENDER}

Tratando da compreensão do empreendedorismo na Psicologia, McClelland (1971), foi o primeiro a enfatizar o aspecto psicológico do empreendedorismo, trazendo a ideia de que esse fenômeno está relacionado com fatores internos, endógenos, e não a fatores externos como recursos naturais, oportunidades, entre outros. Para ele, o que faz o homem explorar oportunidades, usufruir de condições favoráveis de negócio e realizar o progresso econômico são os valores e motivações humanas. Como essas crenças, valores e normas são diferentes em cada cultura e em cada sociedade, o espírito empreendedor divergiria em cada uma com suas especificidades e características particulares. A necessidade por conquistas e realizações é um fator que influencia fortemente na ação empreendedora.

O aporte fornecido por McClelland (1971) é fundamental, pois sustenta grande parte das elaborações propostas ao tema até os dias atuais. Exemplo disso é o impacto da definição do autor nas práticas propostas ao tema 
no Brasil. Para o SEBRAE (Serviço Brasileiro de Apoio às Micro e Pequenas Empresas, 2017), empreendedor é: "aquele que inicia algo novo, que vê o que ninguém vê, enfim, aquele que realiza antes, aquele que sai da área do sonho, do desejo, e parte para a ação", essa definição se mostra compatível com as dimensões listadas por McClelland (1971) reafirmando a importância das elaborações do autor. Acrescenta-se também que as influências de McClelland também foram importantes para Schmidt e Bohnenberger (2009) que realizaram um estudo a fim de identificar características pessoais de empreendedores. Esses autores identificaram que características como autoeficácia, capacidade de assumir riscos calculados, planejamento, visualizar oportunidades, persistência, sociabilidade, inovação e liderança se mostram fundamentais para aqueles que almejam empreender.

Além do conceito de empreendedor, outro conceito relacionado na literatura do empreendedorismo é o intraempreendedor, que caracteriza a pessoa que apresenta comportamentos empreendedores em organizações já existentes. Montenegro (2015) diz que são indivíduos proativos, criativos e inovadores que contribuem com ideias novas e soluções para a empresa como um todo. Ainda segundo o autor, qualquer pessoa dentro da organização pode ser um intraempreendedor, tanto gerentes, diretores, como os demais funcionários. Para que isso seja possível, é necessário que a cultura da empresa seja flexível, aberta a novas sugestões e que os funcionários tenham liberdade de opinar e fazer de acordo com a demanda.

Montenegro (2015) aponta ainda para a importância do ambiente e recursos organizacionais como determinantes à ação intraempreendedora, podendo facilitá-la ou dificultá-la. A descentralização das tomadas de decisões, portanto, é fundamental para que a atividade intraempreendedora seja possível dentro das organizações. Izote, Lana, Gauche e Verdinelli (2013) trazem que muitas empresas proativas já caminham nessa direção visando o aumento da qualidade dos serviços e produtos, bem como a diminuição do custo operacional.

Sendo assim, nota-se a multiplicidade de compreensões sobre o tema, tendo como eixos centrais na caracterização das características pessoais do empreendedor a identificação e exploração de oportunidades por meio de um processo contínuo criativo e em favor da realização do indivíduo empreendedor ou da própria organização (Baron, 2007). Shane e Venkataraman (2000, p. 218) compartilham essa compreensão ao afirmar que 0 empreendedorismo é o "campo que investiga como, por quem e com quais efeitos as oportunidades são descobertas, avaliadas e exploradas para criar bens e serviços futuros". Ademais, há consenso na compreensão de que a identificação e exploração de oportunidades são o cerne das investigações sobre o tema, devendo ser abordado como questão disparadora em investigações (Ardichvili, Cardozo, \& Ray, 2003).

Essas características são importantes, pois interagem de forma dinâmica ao longo da proposição do próprio negócio. Tratando, então, sobre o processo de empreender, verifica-se que abrir um novo negócio envolve diversas fases e, embora existam diferentes proposições, todas elas concordam em três momentos nesse processo: (a) identificação de oportunidade ou pré-lançamento, na qual o empreendedor identifica negócios viáveis que podem ser explorados, (b) desenvolvimento ou fase de lançamento, fase na qual os recursos são obtidos para iniciar o negócio, (c) a fase pós-empreender que envolve o gerenciamento do empreendimento (Baron, 2007).

Dej (2008) também relaciona três etapas nesse processo, pré-lançamento, lançamento e pós-lançamento. Segundo ele, o estágio pré-lançamento é caracterizado por uma potencial inovação, motivação para empreender e por um envolvimento com gestão de negócio. Essa fase de pré-lançamento é caracterizada como o desenvolvimento psicológico da pessoa empreendedora, e do processamento cognitivo de tarefas empreendedoras antecipadas. Essa etapa está ancorada em fatores atitudinais, motivacionais e auto perceptivos da pessoa. 0 lançamento é a abertura 
em si do novo negócio. Já o pós-lançamento dá-se com o proprietário de uma empresa já estabelecida, sustentável, que pode crescer ou falir. Atitudes que favorecem o empreendedorismo, normas subjetivas, autoeficácia empresarial, os quais são condições necessárias, mas não suficientes para que alguém se torne empreendedor (Moriano, Zarnowska, \& Palací, 2007).

Em síntese, se observa que os conceitos e definições associados ao empreendedorismo são multideterminados, com questões de diversos níveis, exploradas por diferentes áreas (Dej, 2008). No presente estudo, adota-se a definição de que o empreendedorismo e, consequentemente, o sujeito empreender é aquele que propõe 0 próprio negócio. Por esse motivo, restringem-se as análises propostas às fases do processo de empreender, abrangendo variáveis individuais e contextuais (Baron, 2007). O processo empreendedor analisado no escopo da investigação é caracterizado pelas experiências de jovens empreendedores, cujo enfoque se dá por meio de abordagem processual e descritiva. Essa compreensão é importante no presente momento, pois mesmo com a elevada participação de jovens na criação de novas empresas existem poucos estudos qualitativos com essa parcela da população (Carvalhal et al., 2012; Veiga \& Parreira, 2015).

MÉTODO

\section{Amostra}

O presente estudo possui um caráter qualitativo e para determinar o tamanho da amostra foi adotado o critério de saturação teórica (Francis, 2010; Mayan, 2001). A saturação teórica ocorre quando o pesquisador depreende que não são apresentados novos dados e que os conceitos teóricos estão contemplados nos achados obtidos (Saumure \& Given, 2008). Por sua vez, os critérios de inclusão dos participantes do presente estudo foram: (a) ser proprietário de um negócio existente há pelo menos um ano, (b) ter entre 18 e 29 anos de idade, sendo o limiar superior definido conforme Estatuto da Juventude (2013), (c) concordar em participar da pesquisa e assinar o Temo de Consentimento Livre e Esclarecido - TCLE. Assim, considerando os critérios estabelecidos foram selecionados por conveniência, utilizando a rede de contato dos pesquisadores, por meio de snowball - técnica bola de neve (Handcock \& Gile, 2011), 6 empreendedores, sendo um homem e cinco mulheres. Na Tabela 1 é feita uma descrição dos participantes do estudo, sendo atribuído um nome fictício a cada um dos participantes para assegurar o anonimato dos mesmos.

\section{Instrumentos}

Foi utilizado um roteiro de entrevista semiestruturada com diferentes questões disparadoras para direcionar a verbalização dos participantes ao tema. Algumas questões podem ser exemplificadas, a seguir: (a) Conte-me sobre o seu negócio e como você o iniciou, (b) Relate-me as dificuldades que você enfrentou ao iniciar 0 seu negócio, (c) Conte-me o que é ser empreendedor para você. 


\section{Procedimentos}

O estudo foi submetido a um comité de ética em pesquisa com seres humanos e recebeu parecer consubstanciado favorável (CAAE: 80489417.3.0000.5152). A coleta de dados por meio da entrevista foi agendada segundo a disponibilidade do participante em sala de atendimento psicológico de uma clínica escola, sendo conduzida individualmente em aproximadamente 50 minutos. Foi empregado um gravador de som para registro do áudio das entrevistas, que foram transcritas pelos pesquisadores e, após a transcrição, apagadas.

\section{Análise de dados}

Para análise de dados foi realizada a análise de conteúdo categorial por frequências (Bardin, 2010). Por meio desse referencial, a entrevista foi analisada em dois níveis diferentes e complementares, abrangendo decifração estrutural, que aborda o conteúdo de uma forma não sistemática, flexível e em função do próprio material verbal, e a transversalidade temática. As etapas seguidas foram: transcrição dos áudios, leitura flutuante dos registros escritos, formulação dos agrupamentos temáticos por critério a posteriori, e, por fim, descrição dos conteúdos em termos de frequência categorial. Salienta-se que o material categorizado foi submetido para análise para dois juízes especialistas externos com expertise na área de Empreendedorismo e Gestão, os quais apresentaram 94\% de convergência com a estrutura proposta.

\section{RESULTADOS}

A partir da análise do corpus das entrevistas foram selecionadas as unidades de análise e elaboradas as categorias temáticas, sendo que a seleção das mesmas foi baseada na "conjunção de interdependência entre os objetivos do estudo, as teorias explicativas adotadas pelo pesquisador e por que não dizer as próprias teorias pessoais intuitivas do pesquisador" (Campos, 2004, p. 613). Assim, foram elaboradas três categorias temáticas: 1) características dos empreendedores; 2) motivações para empreender e 3) dificuldades para empreender.

No que concerne às características dos empreendedores verifica-se que assumir riscos, responsável, comunicativo e criativo foram relatados pelos participantes. As motivações descritas pelos entrevistados podem ser divididas em identificação de oportunidades, necessidade, ter uma empresa com confiança, prestígio, influência de terceiros e família. Como dificuldades para empreender, os entrevistados verbalizaram: iniciar o projeto, adesão dos clientes e liderança, falta de planejamento e desgaste físico e mental. As categorias de e o respectivo detalhamento de cada uma delas são dispostos na Tabela 2.

\section{DISCUSSÃO}

As diferentes dimensões encontradas na investigação mostram-se compatíveis com evidências anteriores da literatura. Ao cotejar as características dos empreendedores encontradas na corrente investigação (assumir riscos; comunicativo; responsável; criativo) com aquelas incluídas na literatura há similitudes e ampliações importantes para compreender o processo empreendedor entre jovens. No que concerne a assumir riscos, os achados coadunam com 
as pesquisas anteriores. Para empreender é necessário aos jovens envidar esforços num curso de ação não intentado por outrem, no caso dos negócios inovadores, ou criar algo similar a outro negócio, em ambos os casos é preciso seguir numa direção sem ter a certeza de sucesso (Hisrich \& Peters, 2004; Omerade, Thorgren, Wincent, 2014; Raven, 2001; Araújo, Oliveira, Christo \& Silva, 2012).

Em relação às motivações para empreender, ter prestígio se revela importante para os jovens empreendedores, o que compatibiliza o relato com a literatura sobre o tema. 0 prestígio para os jovens associa-se diretamente com o reconhecimento que, por sua vez, satisfaz a necessidade de realização dos empreendedores (Anderson \& Jack, 2000). 0 empreendedor é altamente motivado por entregar o melhor e ser reconhecido por tanto, tal como relatado pelos entrevistados. Ainda sobre as motivações, a influência de terceiros também é ressaltada como fundamental pelos entrevistados, o que vai ao encontro dos estudos da área, sendo também importante entre jovens empreendedores.

Na literatura os familiares aparecem como um dos motivadores para se iniciar um negócio (Araújo et al., 2012). Nesse estudo, entre os jovens entrevistados, não apenas os familiares, mas a própria rede de contatos serviu como gatilho para se planejar um negócio. Nessa medida, amplia-se a influência de outros na decisão de abrir um negócio. Isso quer dizer que, para os jovens empreendedores investigados, a influência não está circunscrita à parentela, configurando-se mais como um aspecto associado a capacidade de identificar oportunidades de mercado. 0 mesmo acontece no caso dos relatos sobre empreender por necessidade, cuja motivação predominante é a proposição do próprio negócio para a subsistência. Os jovens empreendedores entrevistados se motivaram para empreender por não ter dinheiro e precisar de uma alternativa de renda, o que torna a necessidade uma motivação no processo empreender desse grupo. Na literatura, esse achado é compatível, pois o Brasil é considerado um país com predominância de empreendedorismo por necessidade, assim como acontece em outros países emergentes (Ricca, 2004).

Essa compatibilidade com a literatura também é verificável ao analisar que os relatos sobre motivação para empreender por identificar oportunidades se mostram menos frequentes que aqueles referentes à empreender por necessidade no grupo pesquisado. Quando se trata de empreender por oportunidade o brasileiro cai substancialmente nos indicadores internacionais de empreendedorismo (GEM, 2017). Ou seja, para os brasileiros, a geração de renda para sobrevivência é um fator crucial no ato de criação do negócio em vez das oportunidades, o que se mostrou replicável no relato dos jovens empreendedores entrevistados.

Ainda no que concerne ao emprendedorismo por necessidade, cabe destacar que as maiores taxas de empreendedorismo inicial (negócios com menos de 42 meses de existência) são identificadas em países com baixo desenvolvimento econômico, refletindo a dificuldade de inserção e manutenção no mercado de trabalho (Machado et al., 2015); desse modo, pode-se inferir que a pessoa, muitas vezes, inicia um negócio próprio como única alternativa frente ao desemprego (Greco et al., 2014). Os negócios criados por necessidade, muitas vezes, não tem um planejamento inicial e as decisões são tomadas num processo de adaptação e construção o que contribui para o seu insucesso (Ruppenthal \& Cimadon, 2012).

Analisando-se as dificuldades para empreender, no relato dos jovens, os sintomas físicos e psíquicos diminuem a qualidade da ação empreendedora e do potencial dos entrevistados. Essa questão passa, então, a figurar entre as prioridades da área, com o intuito de integrar às correntes de investigação e intervenção em saúde do trabalhador os empreendedores. Abranger esse sujeito representa a possibilidade de se promover saúde nas organizações e nos 
espaços de trabalho de forma descendente (top down), uma vez que com melhores condições físicas e psicológicas para 0 agente empreender poderá incidir em melhores condições organizativas e de trabalho àqueles vinculados à organização (Buttner, 1992). Salienta-se que, a despeito da importância de se promover saúde nos espaços de trabalho entre todos os agentes, por meio da noção de integralidade, há uma lacuna ao tratar sobre o empreendedor, que deve ser examinada e integrada à área.

A falta de planejamento, outra dificuldade predominante no relato dos entrevistados, também indica um ponto crítico do empreendedorismo. Em partes, isso pode ser explicado pela excessiva burocracia para empreender. Infere-se que essa questão seja central ao tratar sobre o empreendedorismo no contexto brasileiro, pois se observa que as exigências são elevadas em aspectos burocráticos para criar um negócio no Brasil (Campelli, Casarotto Filho, Barbejat \& Moritz, 2011; Melo et al., 2015). Por outro lado, ainda que a sistematização do negócio seja dificultada pela burocracia, outra parte da dificuldade refere-se à limitação pessoal do sujeito para apreender o tema adequadamente. Em síntese, a falta de planejamento se mostra influenciada pela associada à falta de conhecimento dos aspectos legais e competências gerenciais para empreender.

Por isso, é essencial a existência de políticas públicas que apoiem os novos empreendedores, especialmente os mais jovens a fim de que possuam amparo e suporte na formalização do próprio negócio e no desenvolvimento do planejamento e sistematização da proposta. Do contrário, a burocracia e o desconhecimento se manterão como entraves à aplicação do potencial empreendedor dos jovens, tal como relatado pelos entrevistados. Outras dificuldades, como aquelas que podem ser visualizadas pelo relato dos jovens empreendedores nas categorias adesão dos clientes e iniciar o projeto também seriam beneficiadas com essas políticas, uma vez que tanto a operacionalização do negócio, como formas de atingir a clientela são passíveis de aprimoramento ao se considerar práticas de educação empreendedora passíveis de implementação por meio de políticas públicas favoráveis à promoção do empreendedorismo (Cortez \& Veiga, 2019; Kuratko, 2005; Martin, McNally, \& Kay, 2013).

Ainda sobre as dificuldades, analisando-se as incompatibilidades existentes entre os relatos dos participantes com a literatura, destaca-se a liderança, que é uma competência associada ao empreendedorismo, mas que não emergiu na fala dos sujeitos entrevistados como essencial. Pelo contrário, na presente investigação os jovens empreendedores relataram dificuldade em liderar, dissociando da imagem social do empreendedor a figura de grande líder e atribuindo a liderança a um papel estritamente contingencial frente às atribuições cotidianas do empreendedor. Depreende-se que essa dissonância com a literatura pode ser explicada pelo estágio do negócio dos jovens participantes. Como observado, o negócio ainda está centrado na figura dos fundadores e sua identidade se mescla com a da empresa devido ao estágio inicial em que as empresas dos jovens empreendedores se encontram.

Por exemplo, o DJ e a designer de sobrancelhas ainda definem a centralidade das práticas das suas empresas, o que pode diminuir a importância da liderança de forma expandida, tal como proposto pela literatura que associa 0 empreendedor ao grande líder, pela presença física deles ao todo tempo no espaço de trabalho. No futuro, com o crescimento da organização, é possível que eles passem a considerar essa competência como relevante em vez de simplesmente uma obrigação, porque terão que treinar novos funcionários, abrir novas lojas, de forma que, em estágios ulteriores do empreendimento, a liderança passará a ser requerida (Souza, Pelissari, Gonzales, \& Margoto, 2012). Um aspecto positivo dessa evidência é que, ainda que torne a expressão do empreendedorismo mais difícil, é possível iniciar um negócio sem grandes competências associadas à liderança, a qual pode ser desenvolvida com o tempo. Neste sentido, também se demanda pela promoção de competências associadas à liderança, com o intuito de 
facilitar o desenvolvimento futuro dos negócios propostos por jovens empreendedores (Lima, Lopes, Nassif, \& Silva, 2015; Martin et al., 2013).

\section{CONSIDERAÇÕES FINAIS}

O presente estudo visou identificar motivações e dificuldades enfrentadas por jovens empreendedores. Além dos facilitadores e dificultadores no processo de empreender, o estudo trouxe características pessoais relevantes nesse processo. Para iniciar um novo negócio são requeridas habilidades como assunção de riscos, criatividade e de comunicação, ademais, na identificação de identificação de novas oportunidades de negócio a família e as amizades - networking, têm um papel importante. Para a amostra pesquisada, o negócio se constitui como uma forma de se obter prestígio através do trabalho, na medida em que o jovem empreendedor se destaca no seu ramo de atuação. $\quad$ No que tange às dificuldades enfrentadas pelos jovens entrevistados, retoma-se a importância de atuar frente à saúde ocupacional do indivíduo que trabalha como empreendedor, bem como se faz preciso sistematicamente políticas públicas para simplificar as condições burocráticas de criação dos negócios e desenvolver competências associadas à liderança e planejamento entre os jovens.

O empreendedorismo tem grande potencial para desenvolvimento econômico e social de um país, todavia o empreender por identificação de oportunidades possui maiores chances de lograr êxito que o empreender por necessidade. Na presente pesquisa, identificou-se que entre os motivos para iniciar um negócio está à necessidade de subsistência, assim, entende-se que é fundamental o desenvolvimento de políticas públicas e um ambiente que ofereça melhores condições para a inserção e manutenção dos jovens no mercado de trabalho.

Em suma, assegurar condições para a efetivação do empreendedorismo jovem perpassa por articular teoria e prática em busca de evidências que otimizem condições de saúde, educação e desenvolvimento pessoal para que a juventude possa ascender socialmente ao propor o próprio negócio, ocasionando maior desenvolvimento econômico a todos envolvidos ao longo do processo empreendedor. Os debates não se esgotam aqui sobre 0 empreendedorismo entre jovens, mas espera-se que o estudo tenha suscitado novos questionamentos sobre esse processo multideterminado e complexo, cuja importância se respalda na centralidade da questão para 0 desenvolvimento econômico e social em nosso contexto atual.

\section{REFERÊNCIAS}

Anderson, A. R., \& Jack, S. L. (2000). The production of prestige: an entrepreneurial viagra. The International Journal of Entrepreneurship and Innovation, 1(1), 45-56. dx.doi.org/10.5367/000000000101298504

Araújo, R., Oliveira, F., Christo, R., \& Silva, D. (2012). Empreendedorismo: uma investigação na evolução da perspectiva empreendedora dos estudantes de uma IES privada no Rio Grande do Norte. Revista Eletrônica de Estratégia \& Negócios, 5(1), 28-66. doi.org/10.19177/reen.v5e1201228-66.

Ardichvili, A., Cardozo, R., \& Ray, S. (2003) A theory of entrepreneurial opportunity identification and development. Journal of Business Venturing, 18(1), 105-123. doi.org/10.1016/S0883-9026(01)00068-4.

Baggio, A., \& Baggio, D. (2015). Empreendedorismo: Conceitos e definições. Revista de Empreendedorismo, Inovação e Tecnologia, 1(1), 25-38. doi.org/10.18256/2359-3539/reit-imed.v1n1p25-38. 
Baldin, N., \& Munhoz, E. M. B. (2011). Snowball (bola de neve): uma técnica metodológica para pesquisa em educação ambiental comunitária. Anais do X Congresso Nacional de Educação. PUCPR: Curitiba.

Bardin, L. (2010). Análise de conteúdo. Lisboa: Edições70.

Baron, R. A. (2007). Entreprenrurship: a process perspective. In L. R. Baum, M. Frese \& R. Baron (Orgs.), The psychology of entrepreneurship (pp. 19-39). New Jersey, EUA: Lawrende Erlabaum Associates.

Bittar, F. S. O., Bastos, L. T., \& Moreira, V. L. (2014). Reflexões sobre o Empreendedorismo: uma Análise Crítica na Perspectiva da Economia das Organizações. Revista de Administração da UFSM, 7(1),

$65-80$ doi.org/10.5902/198346597318.

Borges, C., Filion, L. J., \& Simard, G. (2008). Jovens empreendedores e o processo de criação de empresas. RAM. Revista de Administração Mackenzie, 9(8), 39-63. doi.org/10.1590/S1678-697120080000800004.

Brasil. (2012). Oportunidade e necessidade. Recuperado http://www.brasil.gov.br/economia-e-emprego/2012/02/oportunidade-e-necessidade.

Bulgacov, Y. L. M., Cunha, S. K., Camargo, D., Meza, M. L., \& Bugacov, S. (2011). Jovem empreendedor no Brasil: a busca do espaço da realização ou a fuga da exclusão?. Revista de Administração Pública - RAP, 45(3), 695-720. Recuperado de http://www.scielo.br/pdf/rap/v45n3/07.pdf

Buttner, E. H. (1992). Entrepreneurial stress: is it hazardous to your health?. Journal of Managerial Issues, 4(2), 223-240. Recuperado de https://www.jstor.org/stable/40603932

Campos, C. J. G. (2004). Método de análise de conteúdo: ferramenta para a análise de dados qualitativos no campo da saúde Revista Brasileira de Enfermagem, Brasília (DF), 57(5), 611-614. Recuperado de http://www.scielo.br/pdf/reben/v57n5/a19v57n5.pdf

Campelli, M. R., Casarotto Filho, N., Barbejat, M. R. P., \& Moritz, G. O. (2011). Empreendedorismo no Brasil: situação e tendências. Revista de Ciências da Administração, 13(29), 133-151. Recuperado de http://www.redalyc.org/articulo.oa?id=273519438007

Cantillon, R. (1755/2001). Essay on the nature of commerce in general. New Brunswick, Canadá: Tansaction Publishers.

Carvalhal, F., Leão, A. L. \& Teixeira, R. V. (2012). Empreendedorismo Jovem: Perfil E Motivações De Empreendedores Em Aracaju, Sergipe. RPCA - Rio de Janeiro, 6(4), 124-143. doi.org/10.12712/rpca.v6i4.227

Confederação Nacional de Jovens Empresários - CONAJE. (2016). Perfil do Jovem Empreendedor Brasileiro. Recuperado de http://conaje.com.br/projetos/pesquisa-conaje/

Cortez, P. A., \& Veiga, H. M. (2018). Características pessoais dos empreendedores: clarificação conceitual dos construtos e definições da literatura recente (2010-2015). Estudos Interdisciplinares em Psicologia, 9(3), 58-79. doi: 10.5433/2236-6407.2018v9n3p58

Cortez, P., \& Veiga, H. (2019). Intención emprendedora en la universidad. Ciencias Psicológicas, 13(1), 134-149. doi:10.22235/cp.v13i1.1815

Dantas, E. B. (2008). Empreendedorismo e Intra-Empreendedorismo. Recuperado de http://www.bocc.ubi.pt/pag/dantas-edmundo-empreendedorismo.pdf 
Dej, D. (2008). The nature of entrepreneurial motivation. In J. A. M. Leon, M. Gorgievski, \& M. Lukes (Orgs.), Teaching psychology of entrepreneurship: Perspective from six European countrie (pp. 71-102). Madrid, Spain: Universidad Nacional de Educación a Distancia Madrid.

Ferreira, A. S. M., Loiola, E., \& Gondim, S. M. G. (2017). Preditores individuais e contextuais da intenção empreendedora entre universitários: revisão de literatura. Cadernos EBAPE.BR, 15(2), 292-308.doi: 10.1590/1679-395159595

Francis, J. J. et al. What is an adequate sample size? (2010). Operationalising data saturation for theory-based interview studies. Psychology and Health, UK, 25(10), 1229- 1245. http://dx.doi.org/10.1080/08870440903194015

Frese, M., \& Gielnik, M. M. (2014). The psychology of entrepreneurship. Annual Review of Organizational Psychology and Organizational Behavior, 1, 413-438. doi.org/10.1146/annurev-orgpsych-031413-091326.

Global Entrepreneurship Monitor - GEM (2017). Global Entrepreneurship Monitor Global Report 2016/1 Recuperado de http://gemconsortium. org/report/49812

Gorgievski, M. J., \& Stephan, U. (2016). Advancing the Psychology of Entrepreneurship: A Review of the Psychological Literature and an Introduction. Applied Psychology: An International Review, 65(3), 437-468. doi.org/10.1111/apps.12073.

Greco, S. M. de S. S. (Coord.) et al. (2014). Empreendedorismo no Brasil. Curitiba: IBQP.

Hisrich, R. D., \& Peters, M. P. (2004). Empreeendedorismo. Porto Alegre: Bookman.

Kirzner, I. M. (1979). Perception, Opportunity and Profit. Chicago, IL: University of Chicago Press.

Kirzner, I. M. (1997). Entrepreneurial discovery and the competitive market process: an Austrian approach. Journal of Economic Literature, 35(1), 60-85. Recuperado de https://www.jstor.org/stable/2729693

Kuratko, D. F. (2005). The emergence of entrepreneurship education: Development, trends, and challenges. Entrepreneurship Theory and Practice, 29(5), 577-597. doi.org/10.1111/j.1540-6520.2005.00099.x

Lei 12.852, de 05 de agosto de 2013. (2013). Presidência da República. Estatuto da Juventude e dispõe sobre os direitos dos jovens, os princípios e diretrizes das políticas públicas de juventude e o Sistema Nacional de Juventude - SINAJUVE. Recuperado de http://www.planalto.gov.br/ccivil_03/_ato2011-2014/2013/lei//12852.htm

Leon, J. A. M., Gorgievski, M., \& Lukes, M. (2008). Teaching psychology of entrepreneurship: Perspective from six European countries. Madrid, Spain: Universidad Nacional de Educación a Distancia Madrid.

Lima, E., Lopes, R. M. A., Nassif, V. M. J., \& Silva, D. (2015). Ser seu Próprio Patrão? Aperfeiçoando-se a Educação Superior em Empreendedorismo. Revista de Administração Contemporânea, 19(4), 419-439. doi.org/10.1590/1982-7849rac20151296.

Lizote, S. A., Lana, J., Gauche, S., \& Verdinelli, M. A. (2013). Comportamento intraempreendedor: um estudo em instituições de ensino superior. Revista Gestão Universitária na América Latina - GUAL, 6(1), 233-252. doi.org/10.5007/1983-4535.2013v6n1p233.

Machado, C. G., Cruz, D. B. F., Chinelato, F. B., \& Silva, L. C. F. (2015). Empreendedorismo em cenários complexos: uma visão da realidade atual e futura no Brasil a partir de análise comparativa. Revista de Administração IMED, 2015, 5(2), 153-165. doi: 10.18256/2237-7956/raimed.v5n2p153-165 
Martin, B. C., McNally, J. J., \& Kay, M. J. (2013). Examining the formation of human capital in entrepreneurship: A meta-analysis of entrepreneurship education outcomes. Journal of Business Venturing, 28(2),

211-224. doi.org/10.1016/j.jbusvent.2012.03.002

Mayan, M. J. (2001). An Introduction to Qualitative Methods: a training module for students and professionals. Edmonton: International Institute for Qualitative Methodology.

McClelland, D. C. (1971). Entrepreneurship and achievement motivation: approaches to the science of sócio-economic development. In P. Leygel (Org.). Paris: UNESCO.

Melo, F. L. N. B., Sampaio, L. M. B., \& Oliveira, R. L. (2015). Corrupção Burocrática e Empreendedorismo: Uma Análise Empírica dos Estados Brasileiros. Revista de Administração Contemporânea, 19(3), 374-397. Recuperado de http://www.scielo.br/scielo.php?script=sci_arttext\&pid=\$1415-65552015000300374\&lang=pt

Montenegro, M. C. (2015). Empreendedorismo e intraempreendedorismo: a bola da vez. Biblioteca SEBRAE.

Moriano, J. A., Zarnowska, A., \& Palací, F. J. (2007). Entrepreunership as a process. In J. A. M. León, \& M. Gorgievski (Orgs.), Psychology of Entrepreunership: research and education (p. 32-38). Madri, Espanha: Universidad Nacional de Educación a Distancia.

Obschonka, M., Silbereisen, R. K., \& Schmitt-Rodermund, E. (2010). Entrepreneurial intention as developmental outcome. Journal of Vocational Behavior, 77(1), 63-72. doi.org/10.1016/j.jvb.2010.02.008.

Omorede, A., Thorgren, S., \& Wincent, J. (2014). Entrepreneurship pscychology: a review. Internaticonal Entrepreneurship and Mangement Journal, 11(4), 743-768. doi: doi.org/10.1007/s11365-014-0307-6

Raven, J. (2001). Competence in the Learning Society. New York: Oxford.

Ricca, J. L. (2004). Sebrae: o jovem empreendedor. Estudos Avançados, 18(51), 69-75. doi.org/10.1590/S0103-40142004000200004.

Ruppenthal, J. E., \& Cimadon, J. E. (2012). O processo empreendedor em empresas criadas por necessidade. Gestão \& Produção, 19(1), 137-149. https://doi.org/10.1590/S0104-530X2012000100010

Sarfati, G. (2013). Estágios de desenvolvimento econômico e políticas públicas de empreendedorismo e de micro, pequenas e médias empresas (MPMEs) em perspectiva comparada: os casos do Brasil, do Canadá, do Chile, da Irlanda e da Itália. Revista de Administração Pública, 47(1), 25-48. doi.org/10.1590/S0034-76122013000100002.

Saumure, K., Given, L. (2008). Data saturation. In: Given, L. M. (Ed.). The SAGE encyclopedia of qualitative research methods. Thousand Oaks, CA: SAGE Publications Ltd. p. 196.

Say, J. B. (2001). A treatise on political economy. New Jersey: Transaction Publishers.

Schimidt, S., \& Bohnenberger, M. C. (2009). Perfil Empreendedor e Desempenho Organizacional. Revista de Administração Contemporânea, 13(3), 450-467. doi.org/10.1590/S1415-65552009000300007.

Schumpeter, J. (1983). A Teoria do Desenvolvimento Econômico. São Paulo: Abril Cultural.

Schumpeter, J. (1984). Capitalismo, socialismo e democracia. Rio de Janeiro, RJ: Zahar Editores.

Serviço Brasileiro de Apoio às Micro e Pequenas Empresas - SEBRAE. (2017). O que é ser empreendedor? Recuperado

http://www.sebrae.com.br/sites/PortalSebrae/bis/o-que-e-ser-empreendedor,ad17080a3e107410VgnVCM1000003b74 010aRCRD. 
Shane, S., \& Venkatraman, S. (2000). The promise of entrepreneurship as a field of research. Academy of Management Review, 25(1), 217-226. doi.org/10.2307/259271.

Shook, C.L., Priem, R. L., \& McGee, J.E. (2003). Venture creation and the enterprising individual: a review and synthesis. Journal of Management, 29(3), 379-99. d doi:10.1016/S0149-2063(03)00016-3oi

Sinha, P. K., Singh, B. K., Singh, P., \& Burman, R. R. (2016). Factors for Selection of Entrepreneurial Carrier by Youth Trainees of Entrepreneurship Development Programme. Indian Research Journal of Extension Education,16(2), 31-36. Recuperado de https://seea.org.in/irjee/browse_volume.php?vol_no_id=v162

Souza, J. B., Pelissari, A., Gonzales, I. V., \& Margoto, J. B. (2012). Empreendedorismo: fatores de sucesso e insucesso de micro e pequenas empresas. Gestão Contemporânea, 2(1), 93-121. Recuperado de https://www.aedb.br/seget/arquivos/artigos11/1143.pdf

Vale, G. M. V. (2014). Empreendedor: origens, concepções teóricas, dispersão e integração. RAC - Revista de Administração Contemporânea, 18(6), 874-891. doi.org/10.1590/1982-7849rac20141244.

Vale, G. M. V., Corrêa, V. S., \& Reis, F. S. (2014). Motivações para o empreendedorismo: necessidade versus oportunidade. RAC - Revista de Administração Contemporânea, 18(3), 311-327.

Valentim, E. C. D. R. B., \& Peruzzo, J. F. (2018). 0 empreendedorismo nas políticas públicas de trabalho e geração de renda. Argumentum, 10(1), 261-275.

http://periodicos.ufes.br/argumentum/article/download/18362/13204

Van Praag, C. M., \& Versloot, P. H. (2007). What is the value of entrepreneurship: A review of recente research. Small Business. Economics, 29(4), 351-82. doi.org/10.1007/s11187-007-9074-x.

Veiga, H. M. S., Demo, G., \& Neiva, E. R. (2017). The Psychology of Entrepreneurship. Em E. Neiva; C. Torres; H. Mendonça. (Orgs.). Organizational Psychology and Evidence-Based Management: What Science says about Practice. New York City, EUA: Springer, 135-156.

Veiga, H. M. D. S., \& Parreira, S. M. (2015). Perfil empreendedor: análise de suas relações com valores relativos ao trabalho e auto-eficácia para criar. Revista Gestão Organizacional, 8(3), 1-25. Recuperado de http://www.spell.org.br/documentos/ver/41912/perfil-empreendedor--analise-de-suas-relacoes-com-valores-relativos-ao -trabalho-e-auto-eficacia-para-criar-

Wiklund, J., Davidsson, P., Audretsch, D. B. \& Karlsson, C. (2011). The Future of Entrepreneurship Research. Entrepreneurship Theory and Practice, 35(1), 1-9. doi.org/10.1111/j.1540-6520.2010.00420.x. 


\section{Lista de Tabelas}

Tabela 1 - Descrição dos participantes do estudo

\begin{tabular}{lll}
\hline Participante & Ramo de atuação & Organização \\
\hline 1 Letícia & Beleza & Foi criada há um ano. \\
2 Paula & Entretenimento & $\begin{array}{l}\text { Tornou-se proprietária há um ano. 21 funcionários } \\
\text { freelance. }\end{array}$ \\
3 José & Comércio & Está no ramo há 6 anos. 1 funcionária \\
4 Maria & Beleza & Foi criada há 5 anos. \\
5 Camila & Beleza & Foi criada há 15 anos. \\
6 Giovana & Entretenimento & Foi criada há 3 anos. \\
\hline
\end{tabular}

Tabela 2 - Descrição das categorias temáticas

\begin{tabular}{|c|c|c|c|c|}
\hline Dimensão & Definição & Exemplo de fala & Referencial & Frequência \\
\hline \multicolumn{5}{|c|}{ CARACTERÍSTICAS DOS EMPREENDEDORES } \\
\hline Assumir riscos & $\begin{array}{l}\text { Arriscar-se frente às oportunidades de } \\
\text { negócio }\end{array}$ & $\begin{array}{l}\text { "Eu não fico muito abalada, acho que eu sofro mais em } \\
\text { começar algo do que se der errado e eu simplesmente terminar, } \\
\text { eu não sofro com isso" (Maria) } \\
\text { "Eu acho que tudo é uma oportunidade, depende do ponto de } \\
\text { vista que você tá vendo aquilo e o que você quer fazer com } \\
\text { aquilo, então assim, eu tentei pegar todas que apareceram no } \\
\text { meu caminho" (Paula) } \\
\text { "a gente foi na cara e na coragem sem ninguém como } \\
\text { exemplo" (José). }\end{array}$ & $\begin{array}{l}\text { Schmidt } \\
\text { Bohnenberger } \\
\text { (2009) }\end{array}$ & 4 \\
\hline Comunicativo & $\begin{array}{l}\text { Comunicar-se com facilidade, sendo } \\
\text { franco, expansivo e afável }\end{array}$ & $\begin{array}{l}\text { "muito simpática, extrovertida, consigo me adaptar a qualquer } \\
\text { pessoa..." (Letícia); } \\
\text { "muito comunicativa" (Giovana) } \\
\text { "ser social, eu converso bastante" (José) }\end{array}$ & $\begin{array}{l}\text { Schmidt } \\
\text { Bohnenberger } \\
(2009)\end{array}$ & 2 \\
\hline Responsável & $\begin{array}{l}\text { Responder pelos próprios atos ou pelos } \\
\text { de outrem, cumprindo os } \\
\text { compromissos firmados }\end{array}$ & $\begin{array}{l}\text { "responsabilidade, acho que eu tenho bastante... compromisso } \\
\text { né..." (Maria); } \\
\text { "...eu também acho que sou uma pessoa responsável” (Paula) }\end{array}$ & $\begin{array}{l}\text { Schmidt } \\
\text { Bohnenberger } \\
(2009)\end{array}$ & 2 \\
\hline Criativo & $\begin{array}{l}\text { Ser criativo e imaginativo, capaz de } \\
\text { propor práticas com qualidade }\end{array}$ & $\begin{array}{l}\text { "Caprichosa, detalhista, perfeccionista" (Camila); } \\
\text { "criativa" (Paula). }\end{array}$ & $\begin{array}{l}\text { Schmidt } \\
\text { Bohnenberger } \\
(2009) \\
\text { Araújo et a } \\
(2012)\end{array}$ & 2 \\
\hline
\end{tabular}

MOTIVAÇÕES PARA EMPREEENDER

\begin{tabular}{|c|c|c|c|}
\hline Ter prestígio & $\begin{array}{l}\text { Ter uma empresa reconhecida no } \\
\text { mercado e que tenha valor perante os } \\
\text { concorrentes }\end{array}$ & $\begin{array}{l}\text { "Eu quero que as pessoas olhem para aquilo ali como se fosse } \\
\text { a melhor balada da cidade..." (Paula); } \\
\text { "... eu sou a melhor designer de sobrancelha..." (Letícia); } \\
\text { "Quero que passe confiança... mostrar o melhor..." (Maria); } \\
\text { "Qualidade, compromisso, pontualidade..." (Camila); } \\
\text { "Que eu sou a melhor que tá fazendo aquilo..." (Giovana); } \\
\text { "Que as pessoas vejam muito como um ambiente pra que elas } \\
\text { possam ver, sentir o amor que ela tem..." (José) }\end{array}$ & $\begin{array}{l}\text { Anderson e Jack } \\
(2000)\end{array}$ \\
\hline Família & Possuir familiares com negócio próprio & $\begin{array}{l}\text { "Meu tio tem uma clínica..." (Giovana); } \\
\text { "Quando criança minha mãe trabalhava como manicure..." } \\
\text { (Camila); } \\
\text { "Tia Marina que tem a loja x e tia Isabela que começou com } \\
\text { uma lojinha..." (Maria); } \\
\text { "Minha mãe... tem uma loja de roupas" (Letícia). }\end{array}$ & $\begin{array}{l}\text { Vale, Côrrea e } \\
\text { Reis (2014) }\end{array}$ \\
\hline Influência de terceiros & $\begin{array}{l}\text { Receber auxílio de amigos no início do } \\
\text { empreendimento }\end{array}$ & $\begin{array}{l}\text { "Eu tive um relacionamento um tempo atrás com uma Dj..." } \\
\text { (Paula); } \\
\text { "minha mãe trabalhava como manicure e eu sempre achei } \\
\text { interessante..." (Camila); } \\
\text { "me convidaram..." (Giovana) }\end{array}$ & 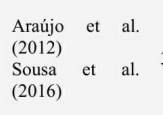 \\
\hline Necessidade & $\begin{array}{l}\text { Ter o negócio como única fonte de } \\
\text { renda, como sobrevivência }\end{array}$ & $\begin{array}{l}\text { "Eu estava cansada de não ter dinheiro..." (Leticia); } \\
\text { "a empresa estava planejando me mandar embora e eu queria } \\
\text { sair, então eu comecei o curso [cabelereira]..." (Maria) }\end{array}$ & Ricca (2004) \\
\hline Identificar oportun & Reconhecer o momento propício $\mathrm{p}$ & $\begin{array}{l}\text { "como o brasileiro gosta muito do futebol, a ideia era trazer } \\
\text { materiais além dessas camisetas pra esse público aqui em }\end{array}$ & $\begin{array}{l}\text { Kirzner (1979) } \\
\text { Ardichvili, et al. }\end{array}$ \\
\hline
\end{tabular}


Tabela 2 - Descrição das categorias temáticas (cont.)

\begin{tabular}{|c|c|c|c|c|}
\hline Dimensão & Definição & Exemplo de fala & Referencial & Frequência \\
\hline \multicolumn{5}{|c|}{ DIFICULDADES PARA EMPREENDER } \\
\hline Desgaste físico e mental & $\begin{array}{l}\text { Expressar cansaço relacionado aos } \\
\text { sintomas corporais ou psicológicos }\end{array}$ & $\begin{array}{l}\text { "A noite por si ela é cansativa..." (Giovana); } \\
\text { "Mais é psicológico..." (Camila); } \\
\text { "Muito cansaço... fico ansiosa..." (Maria); } \\
\text { "Apenas cansaço fisico..." (Leticia); } \\
\text { "Eu acho que o mais desgastante não é o trabalho físico, é o } \\
\text { mental..." (Paula); } \\
\text { "Muita energia. Eu vejo que as vezes eu fico fora do trabalho } \\
\text { pensando no trabalho durante a faculdade..." (José). }\end{array}$ & Buttner (1992) & 6 \\
\hline Falta de planejamento & $\begin{array}{l}\text { Ausência de sistematização e } \\
\text { necessidade de improvisar e intuir } \\
\text { soluçōes conforme as demandas } \\
\text { aparecem }\end{array}$ & $\begin{array}{l}\text { "Não, o sistema sou eu mesmo..." (Paula); } \\
\text { "Não tenho nenhum sistema..." (Letícia); } \\
\text { "Não, é o bate boca, se acontece alguma coisa é a conversa } \\
\text { mesmo, o diálogo..." (Maria); } \\
\text { "Os problemas aparecem muito na hora... tem que } \\
\text { improvisar..." (Giovana); "eu converso com ela pra gente ver e } \\
\text { tal o problema..." (José). }\end{array}$ & $\begin{array}{l}\text { Melo, Sampaio e } \\
\text { Oliveira, (2015) }\end{array}$ & 5 \\
\hline Adesão dos clientes & $\begin{array}{l}\text { Adquirir clientela e converter em } \\
\text { comportamento de compra para o } \\
\text { negócio }\end{array}$ & $\begin{array}{l}\text { "Pessoal só compra quando o time tá em cima, muitas } \\
\text { franquias estão fechando..."(José); } \\
\text { "Eu busco sempre novos clientes..." (Letícia). }\end{array}$ & $\begin{array}{l}\text { Souza et al. } \\
(2012) \\
\text { Campelli et al. } \\
(2011)\end{array}$ & 2 \\
\hline Liderança & $\begin{array}{l}\text { Realizar tarefas de líder pela } \\
\text { necessidade organizativa e não pelo } \\
\text { interesse em e capacidade de liderar }\end{array}$ & $\begin{array}{l}\text { "É dificil porque eu trabalho com muita gente que tem a } \\
\text { mesma faixa etária que eu..." (Paula); "eu vejo que fui } \\
\text { obrigado a tomar essa posição..." (José) }\end{array}$ & $\begin{array}{l}\text { Souza et al. } \\
(2012)\end{array}$ & 2 \\
\hline Iniciar o projeto & $\begin{array}{l}\text { Operacionalizar o negócio, definir } \\
\text { capital, pessoal e meios para a } \\
\text { realização da atividade }\end{array}$ & $\begin{array}{l}\text { "Só que eu sofro mais em começar... procurar um local, achar } \\
\text { um lugar bacana..." (Maria); } \\
\text { "Tenho intenção de expandir, montar esmalteria, mas tem que } \\
\text { achar pessoas boas pra trabalhar..." (Camila). }\end{array}$ & $\begin{array}{l}\text { Souza et al. } \\
(2012)\end{array}$ & 2 \\
\hline
\end{tabular}

